\title{
Outbreak of Salmonella enterica serovar Typhimurium phage type DT41 in Danish poultry production
}

\author{
Löfström, Charlotta; Hintzmann, Ann-Sofie; Sørensen, Gitte; Baggesen, Dorte Lau
}

Published in:

Veterinary Microbiology

Link to article, DOI:

10.1016/j.vetmic.2015.04.017

Publication date:

2015

Link back to DTU Orbit

Citation $(A P A)$ :

Löfström, C., Hintzmann, A-S., Sørensen, G., \& Baggesen, D. L. (2015). Outbreak of Salmonella enterica serovar Typhimurium phage type DT41 in Danish poultry production. Veterinary Microbiology, 178(1-2), 167-172. https://doi.org/10.1016/j.vetmic.2015.04.017

\section{General rights}

Copyright and moral rights for the publications made accessible in the public portal are retained by the authors and/or other copyright owners and it is a condition of accessing publications that users recognise and abide by the legal requirements associated with these rights.

- Users may download and print one copy of any publication from the public portal for the purpose of private study or research.

- You may not further distribute the material or use it for any profit-making activity or commercial gain

- You may freely distribute the URL identifying the publication in the public portal 


\section{Accepted Manuscript}

Title: Outbreak of Salmonella enterica serovar Typhimurium phage type DT41 in Danish poultry production

Author: Charlotta Löfström Ann-Sofie Hintzmann Gitte

Sørensen Dorte Lau Baggesen

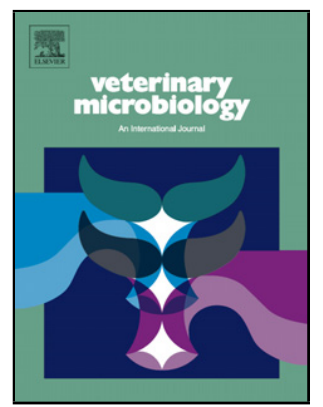

PII:

S0378-1135(15)00162-5

DOI: http://dx.doi.org/doi:10.1016/j.vetmic.2015.04.017

Reference: VETMIC 6968

To appear in:

VETMIC

Received date:

25-2-2015

Revised date:

$17-4-2015$

Accepted date:

20-4-2015

Please cite this article as: Löfström, C., Hintzmann, A.-S., Sorensen, G., Baggesen, D.L.,Outbreak of Salmonella enterica serovar Typhimurium phage type DT41 in Danish poultry production, Veterinary Microbiology (2015), http://dx.doi.org/10.1016/j.vetmic.2015.04.017

This is a PDF file of an unedited manuscript that has been accepted for publication. As a service to our customers we are providing this early version of the manuscript. The manuscript will undergo copyediting, typesetting, and review of the resulting proof before it is published in its final form. Please note that during the production process errors may be discovered which could affect the content, and all legal disclaimers that apply to the journal pertain. 


\section{Highlights}

2 - Outbreak of Salmonella ser. Typhimurium phage type DT41 in Danish broiler production

3 - 47 DT41 and RDNC isolates were analyzed with M LVA and PFGE

4 - 4 PFGE and 9 M LVA types were found; most common M LVA type 2-13-12-8-0212

5 - A spread from broiler breeders to broilers and slaughterhouse was documented

6 


\section{Outbreak of Salmonella enterica serovar Typhimurium phage type DT41 in Danish}

\section{7 poultry production}

8

9 Charlotta Löfström*, Ann-Sofie Hintzmann, Gitte Sørensen, Dorte Lau Baggesen

10

11 Division of Food M icrobiology, National Food Institute, Technical University of Denmark, Mørkhøj Bygade

1219,2860 Søborg, Denmark

13

14 Running head: Salmonella Typhimurium DT41 in Danish poultry

15

$16 *$ Corresponding author:

17

Dr. Charlotta Löfström, National Food Institute, Technical University of Denmark, Mørkhøj Bygade 19, DK-

18 2860 Søborg, Denmark Tel.: +45 358873 50, Fax: +45 358870 01, E-mail: chalo@food.dtu.dk

19

20

Keywords: Salmonella, epidemiology, poultry, genotyping, M LVA, PFGE, DT41, outbreak 


\section{Abstract}

23 Salmonella enterica subspecies enterica serovar Typhimurium (S. Typhimurium) is one of the most

24 prevalent serovars in Europe - where both poultry and poultry related products are common sources of

25 human salmonellosis. Due to efficient control programs, the prevalence of S. Typhimurium in Danish

26 poultry production is very low. Despite this, during the past decades there has been a reoccurring problem

27 with infections with S. Typhimurium phage type DT41 in the Danish poultry production without identifying

28 a clear source. In the end of 2013 and beginning of 2014 an increased isolation of S. Typhimurium DT41 was

29 noted mainly in this production, but also in other samples. To investigate this is in more detail, 47 isolates

30 from egg layers ( $n=5,1$ flock), broilers ( $n=33,13$ flocks), broiler breeding flocks and hatches ( $n=5 ; 2$

31 flocks and 1 environmental hatchery sample), feed $(n=1)$, poultry slaughter house $(n=3$, environmental

32 sample and meat) were typed with multi locus variable number of tandem repeat analysis (M LVA) and

33 pulsed-field gel electrophoresis (PFGE) to investigate the epidemiology of the outbreak. Based on PFGE

34 results isolates were divided into four groups (Simpson's index of diversity (DI) $=0.24 \pm 0.15$ ). Due to the

Iow DI, PFGE was not sufficient to provide information to unravel the outbreak. Based on MLVA typing the

DT41 - (42/47 isolates) and the RDNC isolates (5/47) were split into nine groups ( $\mathrm{DI}=0.65 \pm 0.14)$. When a

maximum divergence at one locus was permitted these could be gathered into four groups. Using this

criterion, combined with epidemiological information, a spread of one type from broiler breeders to period of time and from various sources are in progress. 


\section{Introduction}

Salmonella enterica subspecies enterica serovar Typhimurium (S. Typhimurium) is one of the most frequent causes of human salmonellosis in Europe (EFSA and ECDC, 2013), with poultry as an important reservoir (M ughini-Gras et al., 2014). The prevalence of Salmonella in poultry in Denmark is very low (Anonymous, 2014), but despite this, reoccurring isolations of particularly S. Typhimurium phage type DT41 (hereafter DT41), has been observed in broiler breeder flocks over the past decades (Litrup et al., 2010). DT41 has been isolated from e.g. poultry in different countries (EFSA and ECDC, 2013), wild birds (Pennycott et al., 2006), other animals (Davies et al., 2004; EFSA and ECDC, 2013) and poultry feed (Davies and Wales, 2010). These findings suggest a possibility of transmission between and within poultry flocks, as well as from the environment or via poultry feed (Horton et al., 2013).

Epidemiological characterization of isolates has the key aim to separate related and unrelated isolates, and different typing methods, e.g. phage typing, pulsed-field gel electrophoreses (PFGE) and multiple-locus variable number of tandem repeat analysis (MLVA) have been applied (reviewed by (Wattiau et al., 2011). No general rules for the determination of the optimal resolution and similarity threshold has been established as will depend on the actual bacterium of interest and its genetic nature (EFSA, 2013) For the analysis of typing data it is essential to include epidemiological data, and to balance the discriminatory power and threshold for separation in a way which gives the most meaningful grouping of isolates to obtain the highest level of epidemiological concordance (Struelens, 1996).

Previous studies using M LVA concluded that DT41 did not persist in Danish poultry production, but had an outside source (Litrup et al., 2010). It was speculated that a persisting clone could be genetically unstable, but this hypothesis could not be verified by in-vivo and in-vitro studies (Barua et al., 2013). During the end of 2013 and the beginning of 2014 an increase in the Danish poultry production was again noted for DT41. The aim of this study was to investigate the relation between isolates obtained during this time period 
71 with epidemiological information.

\section{Materials and Methods}

\section{Salmonella strains and epidemiological information}

81 50-56 weeks.

\section{Serotyping and phage typing} abbreviated RDNC.

\section{MLVA and PFGE} 2006) using Xbal (Fermentas, Lifesciences) as restriction enzyme.

\section{Data analysis}

trying to establish a possible common source of the outbreak, using M LVA, PFGE and phage typing together

S. Typhimurium strains were obtained from the strain collection at the Division of Food M icrobiology, National Food Institute, Technical University of Denmark (DTU Food) and were collected through the Danish surveillance programs (Anonymous, 2014) during November 2013 - M arch 2014 (Table 1).

Epidemiological information about the samples and links between production units were kindly provided by poultry industry partners, and supplemented with data from the Danish Herd Register (https://chr.fvst.dk). Isolates from broiler breeder flocks were obtained from flocks in production, and the age of the flocks was

Serotyping of Salmonella isolates was performed by molecular serotyping employing Luminex technology, as previously described (Fitzgerald et al., 2007; M cQuiston et al., 2011), or by slide agglutination with polyclonal antisera (Statens Serum Institut, Copenhagen, Denmark), in accordance with the White Kauffmann - Le M inor scheme (Grimont and Weill, 2007). Phage typing was performed in accordance with international standards (Callow, 1959; Anderson et al., 1977), as described by Public Health England (PHE), Colindale, London, UK. Isolates with reactions that do not confirm with the phage typing scheme were

The M LVA method developed by (Lindstedt et al., 2004) was performed as previously described (Torpdahl et al., 2007). PFGE was carried out according to the PulseNet protocol as previously described (Ribot et al., 
97

Typing and strain metadata were entered into a Bionumerics v. 7.1 database (Applied Maths, Sint-MartensLatem, Belgium) for further analysis. Cluster analysis was made for PFGE band patterns using a position tolerance of $1.5 \%$ and optimization of $1.5 \%$ and results were compared using the Dice coefficient for similarity and unweighted pair group method with arithmetic averages (UPM GA) for clustering.

M LVA allele numbers were analyzed in Bionumerics as character values, and minimum spanning trees (MST) were constructed using categorical coefficients and the Ward algorithm (Ward et al., 2009). The following priority roles were used to create networks: 1 ) M aximum number of $\mathrm{N}$-locus variants $(\mathrm{N}=1)$ Weight: 10000 and 2) M aximum number of $\mathrm{N}$-locus variants ( $\mathrm{N}=2$ ) Weight: 10.

Discriminatory power and its confidence interval were calculated using Simpson's index of diversity, as previously described (Hunter and Gaston, 1988) using BioNumerics and the V-DICE diversity calculator from Public Health England available at: http://www.hpa-bioinformatics.org.uk/cgi-bin/DICI/DICl.pl.

\section{Results}

\section{Description of the outbreak}

From November 2013 to M arch 2014 an increase in the prevalence of S. Typhimurium was noted in the surveillance of the Danish poultry production, where phage type DT41 isolates were found at various stages of the broiler production chain, as well as in a single table egg layer flock and in animal feed (Tables $1 \& 2$ ). The table egg layer flock where DT41 was found in November 2013 had a contemporary infection with another Salmonella phage type (S. Typhimurium DT40). During the study period, S. Typhimurium DT40 was also found in three other layer flocks (data not shown). A search in DTU Food's Salmonella strain collection going back to 2005 revealed that DT41 had previously been isolated from one of these three farms in 2009, and again in 2010, DT41 was isolated from the farm with the DT40/DT41 infection.

\section{In the broiler production chain DT41 was first found in a broiler farm (A1) from producer $A$ in the start of} November 2013 (Table 2). Until the end of M arch 2014 DT41 and/or RDNC phage types was further isolated 
124 from eight broiler farms (six (A2-A7) and two (B1-B2) from farms linked to producer A and B, respectively).

125 DT41 were also isolated from two broiler breeder farms (D1 and D3, in December 2013 and M arch 2014,

126 respectively). None of these farms had a previous record of DT41 isolations. In December 2013 an

127 environmental sample taken at the hatchery (D2) was positive for DT41. This hatchery had been receiving

128 eggs from the broiler breeder farm D1. M oreover, farm D1 had delivered one-day-old chickens to broiler

129 farms A2-A7 and B2.

130

131 In addition, one DT41 strain isolated from a feed sample taken within the frame of the Danish surveillance

132 of feed production (Anonymous, 2014) was obtained. During the period December 2013 to February 2014

133 DT41 was isolated, as part of the surveillance programs, from three samples taken at two different

134 abattoirs (F1 and G1) used for slaughtering of broilers from Producer A, although not the specific flocks

135 from farms A2-A7 where DT41 had been isolated during the same period.

136

\section{Typing of isolates}

138 To further investigate the epidemiology and identify potential sources of the outbreak, 47 DT41 and RDNC

139 isolates were further subtyped using PFGE and MLVA (Figure 1, Table 1). PFGE analysis divided the isolates

140 into four types (types A-D; DI =0.24 $\pm 0.15(95 \% \mathrm{CI})$ ), with 1-4 bands difference between PFGE types (Figure

141 1). M LVA-results showed that the five RDNC phage type isolates, were related to the DT41 isolates and they

142 therefore remained in the analysis of the data. On the basis of M LVA results, the DT41/RDNC isolates were

143 split into nine types ( $\mathrm{DI}=0.65 \pm 0.14(95 \% \mathrm{Cl})$; Figure 1). Locus STTR9 was found to be identical for all

144 isolates (allele 2) and for STTR3 all but one isolate was identical (0212) - the last isolate had the allele 0112.

145 For STTR5 and STTR10 three $(10,12,13)$ and four $(8,9,10,12)$ types were found, respectively. The highest

146 variation was noted for STTR6 where 7 different types were found $(10,11,12,13,14,15,16)$.

147

148 The most common MLVA profile was 2-13-12-8-0212 which was isolated from the hatchery, seven broiler

149 farms (six and one from broiler producer $A$ and $B$, respectively), as well as on two occasions from a

150 slaughterhouse (Figure 1). Merging isolates with only one locus difference resulted in four groups. The most 
151

152

153 154

155 156

\section{7}

158

159

160

161

162

163

164

165

166

167

168

169

\section{Discussion}

171 Salmonella is rarely found in Danish poultry production, and very seldom in broiler breeder flocks

172 (Anonymous, 2014). Nevertheless, reoccurring isolations with S. Typhimurium phage type DT41 has

173 occurred for more than 10 years in particularly the broiler production chain, resulting in the need for

174 expensive and cumbersome actions to be taken by the poultry industry. Previous investigations using M LVA

175 revealed a high diversity in isolates from Danish broiler breeding flocks and it was concluded that no

176 persisting clones of DT41 was present in Danish poultry production, but that the reoccurring infections was

177 due to an outside source (Litrup et al., 2010). However, the instability of the M LVA loci could make it hard 
178 to draw correct conclusions from M LVA data (Litrup et al., 2010; Barua et al., 2013; Wuyts et al., 2013;

179 Dimovski et al., 2014). Highest variation has previously been noted for the STTR6 and STTR5 loci, which is 180 consistent with the data generated in the present study where STTR6 was found to be the most variable,

181 followed by STTR10 and STTR5. To handle this expected variation different models have been suggested, 182 e.g. joining isolates that are differing by one loci (Torpdahl et al., 2007) independent of which loci, or more 183 recently, taking the variation of the different loci into account in a model where isolates with identical 184 alleles for STTR3 and STTR9, but with a one allele difference in the more rapidly changing loci STTR5, STTR6 185 and/or STTR10 are merged (Dimovski et al., 2014).

187 When joining isolates that differed by one locus into groups, the nine M LVA types for the 47 DT41/RDNC 188 isolates were merged into four groups. This criterion has often been applied to find epidemiologically 189 related strains in outbreak investigations (Torpdahl et al., 2007). The differences within the groups that 190 contained more than one isolate each were due to changes in STTR6 (one group), STTR3 (one group) and a 191 combination of changes in STTR5 and STTR6 (one group). If the variability of the different loci was taken 192 into account, as proposed by (Dimovski et al., 2014) one of the groups were split into two, meaning that one broiler isolate (from farm A1) was no longer linked to other broiler isolates from the same flock and to one slaughterhouse isolate (G1). This seems unlikely as there is a strong epidemiological link between these isolates. This result shows that data need to be interpreted with caution and combining typing data with epidemiological information in order to conclude at the highest level of epidemiological concordance

197 (Struelens, 1996). Focus should especially be given to determination of a natural variation within isolates from the same flock and on isolates found on repeated occasions on the same farm. More discriminatory typing methods such as whole genome sequencing (WGS) would most likely be able to reveal a more accurate relationship between these isolates and thus assist in drawing correct conclusions from the data.

202 The convergence between results obtained with M LVA and PFGE was high, although M LVA had a higher DI.

203 There were two M LVA types that contained two different PFGE profiles each, the rest of the M LVA types 204 consisted of isolates with one PFGE type (Figure 1). This high convergence is well recognized in previous 
205

206

studies, although combining PFGE and M LVA results has been shown to increase the DI (Torpdahl et al., 2007; Broschat et al., 2010; Kurosawa et al., 2012). Again, the application of more discriminatory methods would assist obtaining a correct interpretation of data.

The most commonly found M LVA types in this study have, to the best of our knowledge, seldom been isolated from Danish food and veterinary sources, including poultry. However, as M LVA is a relatively new technique, and not being used on all isolates, the data set used for comparison might not be representative of the true occurrence in the Danish animal population. In addition, when comparing the MLVA data for DT41 isolates from 2013/2014 to previous investigations (Litrup et al., 2010; Barua et al., 2013) it can be noted that there is some overlap in the types found. For example, the same M LVA type 2-12-12-8-0212 isolated from one broiler breeding flock in M arch 2014 was also found in chicken from a broiler breeding farm in 2009 (Litrup et al., 2010). To the best of our knowledge, these breeder flocks don't originate from the same farm, but it could be speculated that a persistent infection with this, or similar M LVA types, are established in parts of the Danish broiler breeder production. This persisting clone(s) might then contribute to a continuous spread of DT41 in the production pyramid and a microevolution will lead to a slowly changing genotype, causing variation in e.g. the observed M LVA types. The hypothesis with spread of DT41 from wild birds, as proposed by Litrup et al (2010) and further investigated by Barua et al (2013), has not been addressed in the current study and this, or another outside source such as feed, might still be a possible introduction of the DT41. However, more data on the variation of M LVA types within DT41 from various sources, including wild birds and feed, and a comparison to isolates from previous years are needed to be able to draw more specific conclusions from data.

In conclusion, results from the present study suggest, by using a combination of typing data and epidemiological information, that a spread within the broiler production pyramid had taken place from one broiler breeding flock to seven broiler flocks and further to the abattoir. No typing or epidemiological information could link the other included DT41 isolates from feed, other broiler flocks, or the layer flocks to the outbreak. The source of the sudden increase of S. Typhimurium DT41 remains unclear and to 
232

233 234

\section{5}

236

237

238

239

240

241

242

243

244

245

246

247

248

249

250

251

252

253 Microbiol. 48, 4072-4082.

254

\section{Acknowledgements} declare.

\section{References} University of Denmark.

\footnotetext{
Microbiol. 48, $4072-4082$.
}

investigate this in more detail, further studies using e.g. WGS to obtain a higher discriminatory strength and including isolates from a longer period of time and from various sources are in progress.

Karen M argrethe Wilken is acknowledged for excellent technical assistance, along with the Danish poultry industry for fruitful cooperation, financial support and providing samples and epidemiological data. The funders had no role in study design; in the analysis and interpretation of data; in the writing of the report; and in the decision to submit the article for publication. The authors have no conflicting interests to

Anderson, E.S., Ward, L.R., Saxe, M.J., de Sa, J.D., 1977. Bacteriophage-typing designations of Salmonella typhimurium. J Hyg. (Lond) 78, 297-300.

Anonymous, 2014. Annual Report on Zoonoses in Denmark 2013. National Food Institute, Technical

Barua, H., Lindblom, I.L., Bisgaard, M., Christensen, J.P., Olsen, R.H., Christensen, H., 2013. In vitro and in vivo investigation on genomic stability of Salmonella enterica Typhimurium DT41 obtained from broiler breeders in Denmark. Vet. Microbiol. 166, 607-616.

Broschat, S.L., Call, D.R., Davis, M .A., M eng, D., Lockwood, S., Ahmed, R., Besser, T.E., 2010. Improved identification of epidemiologically related strains of Salmonella enterica by use of a fusion algorithm based on pulsed-field gel electrophoresis and multiple-locus variable-number tandem-repeat analysis. J Clin.

Callow, B.R., 1959. A new phage-typing scheme for Salmonella typhimurium. J Hyg. (Lond) 57, 346-359. 
255

256

257

258

259

260

261

262

263

264

265

266

267

268

269

270

271

272

273

274

275

276

277

Davies, R.H., Dalziel, R., Gibbens, J.C., Wilesmith, J.W., Ryan, J.M., Evans, S.J., Byrne, C., Paiba, G.A., Pascoe, S.J., Teale, C.J., 2004. National survey for Salmonella in pigs, cattle and sheep at slaughter in Great Britain (1999-2000). J Appl. Microbiol. 96, 750-760.

Davies, R.H., Wales, A.D., 2010. Investigations into Salmonella contamination in poultry feedmills in the United Kingdom. J Appl. M icrobiol. 109, 1430-1440.

Dimovski, K., Cao, H., Wijburg, O.L., Strugnell, R.A., M antena, R.K., Whipp, M., Hogg, G., Holt, K.E., 2014. Analysis of Salmonella enterica serovar Typhimurium variable-number tandem-repeat data for public health investigation based on measured mutation rates and whole-genome sequence comparisons. J Bacteriol. 196, 3036-3044.

EFSA, 2013. Scientific Opinion on the evaluation of molecular typing methods for major food-borne microbiological hazards and their use for attribution modelling, outbreak investigation and scanning surveillance: Part 1 (evaluation of methods and applications). EFSA Journal 11, 3502.

EFSA, ECDC, 2013. The European Union Summary Report on Trends and Sources of Zoonoses, Zoonotic Agents and Food-borne Outbreaks in 2011. EFSA Journal 11, 3129.

Fitzgerald, C., Collins, M., van, D.S., M ikoleit, M., Brown, T., Fields, P., 2007. Multiplex, bead-based suspension array for molecular determination of common Salmonella serogroups. J Clin. M icrobiol. 45, 3323-3334.

Grimont, A. D. and Weill, F. X., 2007. Antigenic formulae of the Salmonella serovars, 9th Ed.

Horton, R.A., Wu, G., Speed, K., Kidd, S., Davies, R., Coldham, N.G., Duff, J.P., 2013. Wild birds carry similar Salmonella enterica serovar Typhimurium strains to those found in domestic animals and livestock. Res. Vet. Sci 95, 45-48.

Hunter, P.R., Gaston, M .A., 1988. Numerical index of the discriminatory ability of typing systems: an application of Simpson's index of diversity. J Clin. Microbiol. 26, 2465-2466. 
278

279

280

281

282

283

284

285

286

287

288

289

290

291

292

293

294

295

296

297

298

299

Kurosawa, A., Imamura, T., Tanaka, K., Tamamura, Y., Uchida, I., Kobayashi, A., Hata, E., Kanno, T., Akiba,

M., Yukawa, S., Tamura, Y., 2012. M olecular typing of Salmonella enterica serotype Typhimurium and serotype 4,5,12:i:- isolates from cattle by multiple-locus variable-number tandem-repeats analysis. Vet.

Microbiol. 160, 264-268.

Lindstedt, B.A., Vardund, T., Aas, L., Kapperud, G., 2004. Multiple-locus variable-number tandem-repeats analysis of Salmonella enterica subsp. enterica serovar Typhimurium using PCR multiplexing and multicolor capillary electrophoresis. J Microbiol. M ethods 59, 163-172.

Litrup, E., Christensen, H., Nordentoft, S., Nielsen, E.M ., Davies, R.H., Helmuth, R., Bisgaard, M., 2010. Use of multiple-locus variable-number tandem-repeats analysis (M LVA) typing to characterize Salmonella Typhimurium DT41 broiler breeder infections. J Appl. M icrobiol. 109, 2032-2038.

McQuiston, J.R., Waters, R.J., Dinsmore, B.A., M ikoleit, M .L., Fields, P.I., 2011. M olecular determination of H antigens of Salmonella by use of a microsphere-based liquid array. J Clin. M icrobiol. 49, 565-573.

Mughini-Gras, L., Enserink, R., Friesema, I., Heck, M., van, D.Y., van, P.W., 2014. Risk factors for human salmonellosis originating from pigs, cattle, broiler chickens and egg laying hens: a combined case-control and source attribution analysis. PLoS One 9, e87933.

Pennycott, T.W., Park, A., M ather, H.A., 2006. Isolation of different serovars of Salmonella enterica from wild birds in Great Britain between 1995 and 2003. Vet. Rec. 158, 817-820.

Ribot, E.M ., Fair, M.A., Gautom, R., Cameron, D.N., Hunter, S.B., Swaminathan, B., Barrett, T.J., 2006. Standardization of pulsed-field gel electrophoresis protocols for the subtyping of Escherichia coli 0157:H7, Salmonella, and Shigella for PulseNet. Foodborne Pathog. Dis 3, 59-67.

Struelens, M.J., 1996. Consensus guidelines for appropriate use and evaluation of microbial epidemiologic typing systems. Clin. M icrobiol. Infect. 2, 2-11. 
300 Torpdahl, M., Sorensen, G., Lindstedt, B.A., Nielsen, E.M ., 2007. Tandem repeat analysis for surveillance of

301 human Salmonella Typhimurium infections. Emerg. Infect. Dis 13, 388-395.

302 Ward, G., Hastie, T., Barry, S., Elith, J., Leathwick, J.R., 2009. Presence-only data and the EM algorithm.

303 Biometrics 65, 554-563.

304 Wattiau, P., Boland, C., Bertrand, S., 2011. M ethodologies for Salmonella enterica subsp. enterica

305 subtyping: gold standards and alternatives. Appl. Environ. M icrobiol. 77, 7877-7885.

306 Wuyts, V., M attheus, W., minne de, B.G., Wildemauwe, C., Roosens, N.H., M archal, K., De Keersmaecker,

307 S.C., Bertrand, S., 2013. M LVA as a tool for public health surveillance of human Salmonella Typhimurium:

308 prospective study in Belgium and evaluation of M LVA loci stability. PLoS One 8, e84055.

309

310 


\section{Figures legends}

312 Figure 1. Neighbor joining tree for the 47 Salmonella Typhimurium DT41 and RDNC isolates (stars) divided

313 by M LVA profile, and colored based on PFGE profile. Partitioning is based on a maximum divergence of one

314 locus with M LVA (marked in grey). The sample source with no. of isolates (see Table 1 for an explanation) is

315 shown next to each circle together with M LVA profiles for each group in brackets. The insert shows the

316 PFGE profiles (representative isolates for each profile) compared using the Dice coefficient for similarity

317 and unweighted pair group method with arithmetic averages (UPM GA) for clustering.

318

319 
Table 1. Overview of the 47 included Salmonella isolates together with typing data.

\begin{tabular}{|c|c|c|c|c|c|c|}
\hline Isolate no. & $\begin{array}{l}\text { Received date } \\
\text { (YYYY-MM-DD) }\end{array}$ & $\begin{array}{l}\text { Type of } \\
\text { production }\end{array}$ & Source $^{a}$ & $\begin{array}{l}\text { Phage } \\
\text { type }\end{array}$ & $\begin{array}{l}\text { PFGE } \\
\text { type }\end{array}$ & MLVA type \\
\hline 2013-60-2066-1 & 2013-11-13 & Broilers & A1 & DT41 & $A$ & $2-12-16-12-0212$ \\
\hline $2013-60-2066-2$ & 2013-11-13 & Broilers & $\mathrm{A} 1$ & DT41 & A & $2-12-16-12-0212$ \\
\hline $2013-60-2066-3$ & 2013-11-13 & Broilers & $\mathrm{A} 1$ & DT41 & $A$ & $2-12-16-12-0212$ \\
\hline 2013-60-2066-4 & 2013-11-13 & Broilers & $\mathrm{A} 1$ & DT41 & A & $2-12-16-12-0212$ \\
\hline 2013-60-2089-1 & 2013-11-19 & Broilers & $\mathrm{B} 1$ & RDNC & C & $2-12-10-10-0212$ \\
\hline 2013-60-2151-1 & $2013-11-28$ & Egg layers & $\mathrm{Cl}$ & DT41 & B & $2-12-14-10-0212$ \\
\hline $2013-60-2155-1$ & 2013-11-29 & Egg layers & $\mathrm{C} 1$ & DT41 & B & $2-12-14-10-0212$ \\
\hline $2013-60-2155-2$ & $2013-11-29$ & Egg layers & $\mathrm{Cl}$ & DT41 & B & $2-12-14-10-0212$ \\
\hline $2013-60-2155-3$ & $2013-11-29$ & Egg layers & $\mathrm{Cl}$ & DT41 & B & $2-12-14-10-0212$ \\
\hline $2013-60-2155-4 b$ & 2013-11-29 & Egg layers & $\mathrm{Cl}$ & DT41 & A & $2-12-14-10-0212$ \\
\hline $2013-60-2160-1$ & $2013-12-03$ & Broiler breeders & $\mathrm{D} 1$ & DT41 & A & 2-13-11-8-0212 \\
\hline 2013-60-2182-1 & 2013-12-04 & Broilers & B2 & DT41 & A & $2-13-12-8-0212$ \\
\hline $2013-60-2182-2$ & 2013-12-04 & Broilers & B2 & RDNC & A & $2-13-12-8-0212$ \\
\hline $2013-60-2182-3$ & 2013-12-04 & Broilers & $\mathrm{B} 2$ & DT41 & A & $2-13-12-8-0212$ \\
\hline $2013-60-2182-4$ & 2013-12-04 & Broilers & B2 & DT41 & A & $2-13-12-8-0212$ \\
\hline $2013-60-2206-1$ & 2013-12-05 & Broiler breeders & $\mathrm{D} 1$ & DT41 & $A$ & 2-13-13-8-0212 \\
\hline $2013-60-2206-2$ & 2013-12-05 & Broiler breeders & $\mathrm{D} 1$ & DT41 & A & 2-13-13-8-0212 \\
\hline $2013-60-2210-1$ & 2013-12-09 & Broilers & $\mathrm{A} 2$ & DT41 & A & $2-13-12-8-0212$ \\
\hline $2013-60-2210-2$ & 2013-12-09 & Broilers & $\mathrm{A} 2$ & DT41 & A & $2-13-12-8-0212$ \\
\hline $2013-60-2210-3$ & 2013-12-09 & Broilers & $\mathrm{A} 2$ & DT41 & A & $2-13-12-8-0212$ \\
\hline $2013-60-2210-4$ & 2013-12-09 & Broilers & $\mathrm{A} 2$ & DT41 & A & $2-13-12-8-0212$ \\
\hline $2013-60-2210-5$ & 2013-12-09 & Broilers & $\mathrm{A} 2$ & DT41 & A & $2-13-12-8-0212$ \\
\hline $2013-60-2224-1$ & 2013-12-09 & Broilers & A3 & DT41 & $A$ & $2-13-12-8-0212$ \\
\hline
\end{tabular}




\begin{tabular}{|c|c|c|c|c|c|c|}
\hline $2013-60-2224-2$ & 2013-12-09 & Broilers & A3 & DT41 & $A$ & $2-13-12-8-0212$ \\
\hline $2013-60-2224-3$ & 2013-12-09 & Broilers & $\mathrm{A} 3$ & DT41 & $A$ & $2-13-12-8-0212$ \\
\hline $2013-60-2258-3$ & 2013-12-12 & Broilers & B2 & DT41 & $A$ & $2-13-12-8-0212$ \\
\hline $2013-60-2258-4$ & $2013-12-12$ & Broilers & B2 & DT41 & $A$ & $2-13-12-8-0212$ \\
\hline $2013-60-2244-3$ & $2013-12-11$ & Feed & $\mathrm{E} 1$ & DT41 & $A$ & $2-10-15-9-0212$ \\
\hline 2013-60-2261-1 & 2013-12-16 & Broilers & $\mathrm{A} 1$ & DT41 & $A$ & $2-12-16-12-0112$ \\
\hline $2013-60-2262-1$ & $2013-12-16$ & Broilers & A4 & DT41 & $A$ & $2-13-12-8-0212$ \\
\hline $2013-60-2262-2$ & $2013-12-16$ & Broilers & A4 & DT41 & $A$ & $2-13-12-8-0212$ \\
\hline $2013-60-2262-3$ & $2013-12-16$ & Broilers & A4 & DT41 & D & $2-13-12-8-0212$ \\
\hline $2013-60-2278-1$ & $2013-12-17$ & Broilers & A5 & DT41 & A & $2-13-12-8-0212$ \\
\hline $2013-60-2279-1$ & $2013-12-17$ & Broilers & $\mathrm{A} 2$ & DT41 & $A$ & $2-13-13-8-0212$ \\
\hline $2013-60-2279-2$ & $2013-12-17$ & Broilers & A2 & DT41 & $A$ & $2-13-12-8-0212$ \\
\hline $2013-60-2279-3$ & 2013-12-17 & Broilers & 2 & RDNC & $A$ & $2-13-12-8-0212$ \\
\hline $2013-60-2307-1$ & $2013-12-23$ & Broilers & A6 & DT41 & $A$ & $2-13-12-8-0212$ \\
\hline 2014-60-21-1 & 2014-01-03 & Hatchery & $\mathrm{D} 2$ & DT41 & $A$ & $2-13-12-8-0212$ \\
\hline 2014-60-19-1 & 2014-01-03 & Slaughter house & $\mathrm{F} 1$ & DT41 & $A$ & $2-13-12-8-0212$ \\
\hline $2014-60-28-1$ & 2014-01-07 & Broilers & A7 & DT41 & $A$ & $2-13-12-8-0212$ \\
\hline $2014-60-34-1$ & 2014-01-10 & Slaughter house & $\mathrm{F} 1$ & DT41 & $A$ & $2-13-12-8-0212$ \\
\hline 2014-60-94-1 & $2014-01-22$ & Broilers & B2 & RDNC & $A$ & $2-13-12-8-0212$ \\
\hline $2014-60-94-2$ & 2014-01-22 & Broilers & B2 & RDNC & $A$ & $2-13-13-8-0212$ \\
\hline $2014-60-94-3$ & 2014-01-22 & Broilers & B2 & DT41 & $A$ & $2-13-12-8-0212$ \\
\hline $2014-60-105-1$ & 2014-01-27 & Broilers & $\mathrm{A} 1$ & DT41 & $A$ & $2-12-16-12-0212$ \\
\hline $2014-60-224-1$ & 2014-02-12 & Slaughter house & $\mathrm{G} 1$ & DT41 & $A$ & $2-12-16-12-0212$ \\
\hline $2014-60-427-1$ & $2014-03-25$ & Broiler breeders & D3 & DT41 & $A$ & $2-12-12-8-0212$ \\
\hline
\end{tabular}


Broilers ( $n=2 ; A 2, B 2)$, broiler breeders $(n=2 ; D 1)$

[2-13-13-8-0212]

[2-13-12-8-0212]

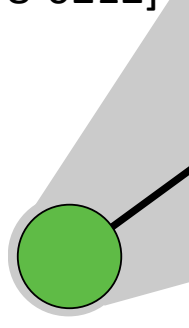

Broiler breeders ( $n=1 ; D 1)$

[2-13-11-8-0212]

Broilers ( $n=5 ; A 1)$, slaughter house $(n=1 ; G 1)$ [2-12-16-12-0212]

Broilers ( $n=1 ; A 1)$ [2-12-16-12-0112]
Broilers ( $n=23 ; A 2-A 7, B 2)$, slaughter house ( $n=2 ; F 1)$, hatchery $(n=1 ; D 2)$

Broilers ( $n=1 ; A 4)$

Egg layers $(n=5 ; C 1)$

[2-12-14-10-0212]

Broilers ( $n=1 ; B 1)$

[2-12-10-10-0212]

Broiler breeders ( $n=1 ;$ D3)

[2-12-12-8-0212]

PFGE profiles

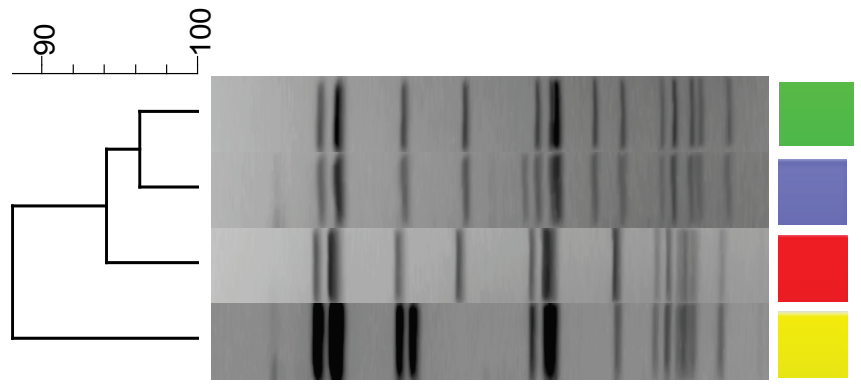

Profile $A(n=41)$

Profile $C(n=1)$

Profile $B(n=4)$

Profile $D(n=1)$ 
Table 2. Overview of the epidemiological data

\begin{tabular}{|c|c|c|c|c|c|c|c|c|c|c|c|c|c|c|c|c|c|c|c|c|c|c|}
\hline \multirow[t]{2}{*}{ Source } & \multirow[t]{2}{*}{ Source $^{a}$} & \multicolumn{19}{|c|}{ No. of events for week no. } & \multirow{2}{*}{\multicolumn{2}{|c|}{ Total }} \\
\hline & & 46 & 47 & 48 & 49 & 50 & 51 & 52 & 1 & 23 & 4 & 5 & 6 & 7 & 8 & 9 & 10 & 11 & 12 & 13 & & \\
\hline \multirow[t]{9}{*}{ Broilers } & $\mathrm{A} 1$ & 1 & & & & & 1 & & & & & 1 & & & & & & & & & & 3 \\
\hline & $\mathrm{A} 2$ & & & & & 1 & 1 & & & & & & & & & & & & & & & 2 \\
\hline & A3 & & & & & 1 & & & & & & & & & & & & & & & & 1 \\
\hline & A4 & & & & & & 1 & & & & & & & & & & & & & & & 1 \\
\hline & A5 & & & & & & 1 & & & & & & & & & & & & & & & 1 \\
\hline & A6 & & & & & & & 1 & & & & & & & & & & & & & & 1 \\
\hline & A7 & & & & & & & & & 1 & & & & & & & & & & & & 1 \\
\hline & B1 & & & & & & & & & & & & & & & & & & & & & 1 \\
\hline & B2 & & & & $1^{c}$ & & & & & & 1 & & & & & & & & & & & 3 \\
\hline Total broilers & & 1 & 1 & 0 & 1 & 2 & 4 & 1 & 0 & 10 & 1 & 1 & 0 & 0 & 0 & 0 & 0 & 0 & 0 & 0 & & 13 \\
\hline Egg layers & $\mathrm{Cl}$ & & & 1 & & & & & & & & & & & & & & & & & & 1 \\
\hline \multirow[t]{2}{*}{ Broiler breeders } & $\mathrm{D} 1$ & & & & 1 & & & & & & & & & & & & & & & & & 1 \\
\hline & D3 & & & & & & & & & & & & & & & & & & & 1 & & 1 \\
\hline Hatchery & D2 & & & & & & & & 1 & & & & & & & & & & & & & 1 \\
\hline
\end{tabular}




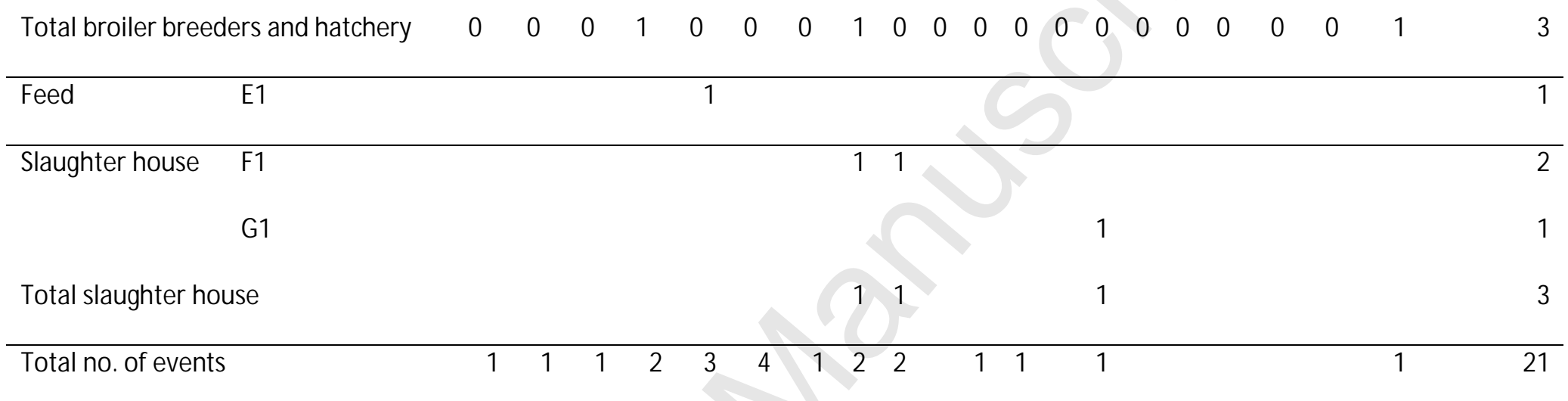

${ }^{a}$ Farm for broilers, broiler breeders and egg layers

${ }^{b}$ Bold numbers (in red) represent the outbreak M LVA single loci variant cluster with types 2-13-12-8-0212, 2-13-11-8-0212, 2-13-13-8-0212 and 2-1212-8-021

'Isolates from the same flock were also obtained in week 50, but were regarded as one case as samples were taken in the same house 8 days apart 